\title{
Make Best Use of Open Experimental Project to Improve Practical Innovation Ability of College Students
}

\author{
Qilei SUN, Bin XU, Kegao Liu, Chengbei WANG, Xinggang WANG \\ Shandong Jianzhu University, Jinan, Shandong, 250101, China
}

\begin{abstract}
Analyzing the defects of the traditional teaching methods of experimentation and the necessity of building an open experimental project, the authors introduce several new methods of how to develop students' innovational ability during the course of building and using the open experimental project. In the running process of opening laboratories in universities currently, there emerged a series of problems, such as the unclear experiment aim and the inadequate research depth caused by students' lacking of guidance, and the insufficient construction of innovation laboratories. All of the above aims at the exploration of the new pattern of university open laboratory management.
\end{abstract}

Keywords: open experimental project, experiment teaching, practical innovation

\section{Introduction}

"Practical innovation ability" is a new concept in the field of education in recent years $^{[1]}$. Some scholars think that the practice innovation ability belongs to the category of practical ability. The changes in practical ability's structure show as the three aspects levels, from low to high: Basic practice ability, Comprehensive practice ability, Practical innovation ability. Practical innovation ability is to show up that it reached an advanced stage of the practical ability, means college students use the enrich knowledge which has been accumulated, through their study constantly in mind, formed in the original thinking, to solve practical problems creatively ${ }^{[2]}$.

The task of higher education is to cultivate the innovative spirit and practical ability of the senior specialized personnel, to meet the social development of high level, high quality talents demand $^{[3]}$. College students learn some theoretical knowledge in class, the open experiment project which will integrate theory with practice, inspire students' interest and innovation enthusiasm, to improve the practical and innovative ability finally. In recent years, universities increase the level of opening laboratory and improvement of its functions. Therefore, how to most efficiently use open experiment project to improve college students' practical innovation ability has become a new question $^{[4]}$.

\section{Problems in the Process of Open Experimental Project Teaching}

\subsection{The teaching content is difficult, the project settings is unreasona- ble.}

The open experimental project requests experiment content reflect basic, advanced, applied and comprehensive, and these aspects in different stages are 
different. Open experiment teaching's construction and development, is a slowly progressive course, can not only change the old content. At present, the verification experiment is a larger proportion; some comprehensive design experiment basic theory linking is not strong and has high repeatability. The experiments are difficult to find the reflection with the basis of the research .The project for the traditional experimental teaching is difficult to let the students in the open experiment improve learning initiative, more difficult to achieve the goal of training innovation ability training.

\subsection{Insufficient investment of opening experimental teaching, and li- mited resources}

With the application of a large number of new technology and new process, together with the deficiency of funds school put into the teaching equipment, The ageing of teaching equipment and the lack of lab resources are becoming increasingly outstanding, so the investment in opening experimental teaching is too little .Determined by the characteristics of opening experimental teaching, it is bound to increase supplies consumption, and damage to the instrument. At the same time, the expansion of the open experimental teaching increases the workload of teachers invisibly. While all these work need a certain amount of capital investment .At present, the work in this area almost has no progress. So it is difficult to reach round-the-clock opening experiment under the existing conditions, which has a direct influence on the improvement of teaching quality, and become the bottleneck of the development of experimental teaching reform.

\subsection{Experimental teaching evaluation is not perfect, the students have- $n$ 't been put forward higher re- quirements.}

Experimental evaluation is a means to check students' mastery of experimental skills, whether be objective and reasonable to the assessment of the students' comprehensive ability or not will affect the enthusiasm of the students to do the experiment, and have a larger impact on the quality of the experimental teaching. So far, most of the experimental teaching is not a separate set course, but has a very small proportion of the course examination scores. The Examination ways of Experimental Teaching stay on the completion of lab report, let alone reflect the experimental teaching content in the final exam, and thus leading to individual students not preview before the experiment, neither nor think during the experiment, and cope with the experimental reports . Designing experiments and creating experiments neither work as lesson nor give credits (at this point, our school has introduced policies to reform, as an item of increasing students' extracurricular credits).

\subsection{Lack of perfect opening experi- mental teaching management sys- tem}

With the expansion of the open experimental teaching, teaching management is becoming more complex, and further requirements for the management of the laboratory have been put forward. The implementation of the open laboratory increases the workload of the laboratory relatively. Opening experimental teaching break the traditional laboratory mode, increase the randomness of student's experiments, which often lead the students to the laboratory to do the experiment 
dispersedly or in a certain period of time? In addition, the opening laboratory tends to prolong the time of the laboratory work. In the course of time arrangement, the management of students, teachers outfit, equipment management and maintenance and so on, still use the old management approach; there is no research to develop an effective approach to solve above problems so far.

\section{Safeguards and Solutions}

\subsection{Safeguards}

To guarantee the smooth progress of the lab opening and improve experimental teaching effects, the following safeguards are absolutely necessary:

1. A rational allocation among the various laboratory instruments is necessary to not only meet the requirements of the laboratory experiments within content, but also the overall planning, integration of resources to build large-scale and precision instrument center, to ensure the normal, safe and efficient use.

2.Protection for the funding of the experiment. Innovative experimentation and open laboratory will certainly create a great increasing expenses, in order to ensure the smooth progress of the teaching reform, it is necessary to set up special funds according to the actual situation of the school, or appropriate allowance according to the laboratory conditions and performance; For projects from the issue of teachers, appropriate scientific research funds allowance can be given; To students' subject group, according to the issues before the report and the meaning and feasibility, a certain amount of funding support can be given too.

3.The guarantee for experimental teaching team. In the treatment of experimental teachers' increasing workload, the school should give these teachers certain support and preferential treatment, such as the issuance of special allowance, tilt in the work assessment and so on, in order to improve their work ethic and enthusiasm.

\subsection{Solutions}

1.Strengthen the cross of subjects, arouse the enthusiasm for innovation

Mutual infiltration and cross between disciplines is one of the driving forces of scientific development, and also is the source of many innovative scientific argument and method. It can help us borrow and introduce some positive results from other disciplines that related to our discipline, it can help us draw nutrition; summarize the new thoughts, new theory and new methods.

When facing difficulties, students discuss with teachers to inspire their thinking, promoting them to consult materials and educating them to study related knowledge by themselves. Through the comprehensive training, students have more intuitive understanding and master to the knowledge learned from books, educate students' ability of using comprehensive knowledge to analyze and solve actual problems, greatly enhancing the students' future learning interest and learning quality.

2.Pay attention to the acceptance of experimental results, strengthen the ability training.

When the experimental project is completed, students submit test reports, papers and products to the lab. Laboratory Partials to carry out summarize and exchange work, such as organizing "the opening experiments" activities, promote the communication between experiment groups, students share their achievements and experience, 
cultivate the students' ability of oral communication and report.

Experiment report will include at least the following five aspects: The purpose of the experiment; the basic train of thought of the experiment; the experimental principle; Experimental phenomena analysis, data processing and result analysis; Review the results and their significance of the experiment. Teacher gives review opinions, takes the multimedia to unify achievement, student himself or herself participates in the experiment project acceptance, the acceptance group work strictly; they give points according to the experimental effect of the completion of the project.

3. Open management to students

The opening of the laboratory is relative to the traditional "closed", the opening of the laboratory should be on the experiment content, it will change the traditional verification experiment for the comprehensive and designing experiments; On management mode, it use modern means implementing the completely open experimental teaching mode, On the time, laboratory open to students in an all-round way from Monday to Sunday of day and night; On the service object, both open between teachers and students, this specialty is to cross major, interdisciplinary, interdisciplinary open between teachers and students; Both teachers and students to our school open, also open to other teachers and students of all types and at all levels; Open to school already, also open to the society.

\section{Summary}

Opening experiment is the national promotion of quality education and the important way of cultivating college teaching reform and creative talents.
Laboratory opening is not only the open time and space, but also a design lab resource allocation. The scientific research team construction and the establishment of the scientific management system are a comprehensive systems engineering. It is compatible with all of the actual situation of colleges and universities, and the experimental teaching system, teaching contents, teaching methods, teaching means to combine, sincere design, reasonable arrangement, in order to truly achieve training students' practical ability, training students' scientific research level, and further improve the quality of teaching.

\section{References}

[1] LIAO Yifan, SUN Shunqing, ZHAO Liang, CHEN Cheng, LUO Ping. Research on Some Problems about College Students' Innovative Experimental Projects and Construction of Opening Laboratories [J]. Journal of Hunan International Economics University, pp.74-76, 2011.

[2] ZHENG Shu-ming, HE Li-jun, WU Qing, HE Rong. On the Significance of Opening Laboratories for the Cultivation of Students' Abilities [J]. Journal of Southwest Agricultural University(Social Science Edition), pp.74-76, 2005.

[3] ZHAO Yang, WANG Feng-hua. On the Quality Guarantee System under the Mode of Open Experimental Teaching [J]. RESEARCH AND EXPLORATION IN LABORATORY, pp.100-103, 2010.

[4] ZHANG Peng. An Elementary Introduction to the Establishment of Open Laboratory [J]. JOURNAL OF GUIZHOU UNIVERSITY OF TECHNOLOGY. pp. 288-290, 2008. 